\title{
Research on Curriculum Reform of Career Planning and Employment Guidance Based on PBL Teaching Method
}

\author{
Zhenrong Zhang \\ Science and Technology College Gannan Normal University \\ Ganzhou, China 341000
}

\begin{abstract}
In the university, most students do not like the College Career Planning and Employment Guidance course. Through many years of teaching practice research, the proposed PBL teaching method can effectively mobilize students to actively participate in teaching, so that students can effectively transform from passive learning to active learning, which has practical guiding significance for the course teaching reform of College Career Planning and Employment Guidance.
\end{abstract}

Keywords-PBL teaching method; college students; career planning and employment guidance; teaching reform

\section{INTRODUCTION}

Under the impact of impetuous social reality, universities are now far away from the "pure land" that people have been keen to explore. Along with the advent of the employment pressure of college graduates, the education authorities have emphasized that the college student employment guidance should go through the whole process of university teaching. The course College Career Planning and Employment Guidance has become particularly important. However, in the actual teaching process, many students think: "You can't solve the work for me in the employment guidance class. How important is this course?" At the same time, the teacher also reflected: "There are no students listening to the Career Planning and Employment Guidance for College Students. Most students are chatting, sleeping, and playing with mobile phones. Such classes do not know how to carry out it." Therefore, the teaching of the Career Planning and Employment Guidance for College Students course has naturally become a tool for many students and individual teachers to complete tasks and obtain credits.

PBL (Problem-Based Learning) is a teaching method pioneered by Barrows, a professor of neurology in the United States, in the 1950 s to train medical students to explore and solve clinical medical problems. It was first implemented at McMaster University in Canada in 1969. The purpose is to enable students to use their existing knowledge and learn new knowledge autonomously from the process of solving problems. In 1983 Schmidt elaborated on the advantages of PBL teaching methods and proposed the use of PBL as a supplement to traditional teaching in medical education. Subsequently, a large number of experts and scholars explored
PBL teaching methods in medical teaching and clinical teaching, resulting in many theoretical achievements. However, few people have explored the PBL teaching method outside the field of medical teaching. According to the database of the knowledge database, we found a total of 8197 scientific research papers involving PBL teaching methods, of which more than $90 \%$ of the articles were developed with medical research. In 2001, the paper "The Application of PBL Teaching Method in Computer Basic Teaching" published by Wang Qing, Xiao Liehong, Mo Xiaohong and Li Zhongzheng first proposed the application of PBL teaching method in teaching outside medicine, boldly carry out the PBL teaching attempt in the teaching, and confirm the practical effect of the PBL teaching method. Under the background of the thoughts of PBL teaching method, this topic in-depth practice research, and put forward the teaching effect of traditional teaching method and PBL teaching method in the Career Planning and Employment Guidance course to conduct a timely comparative study. It proves the feasibility of PBL teaching method in the teaching reform of Career Planning and Employment Guidance.

PBL teaching method is conducive to changing learning habits of students in the course of Career Planning and Employment Guidance, making students become the main body of teaching in the process of teaching, and improving teachers' awareness of problems in teaching. Through discussing the typical problems of Career Planning and Employment Guidance, comprehensive cognitive ability of students can be effectively cultivated and trained. Through the PBL teaching method in the Career Planning and Employment Guidance curriculum reform, to improve ability of students to analyze problems and solve problems as a teaching orientation, fully develop the potential and social adaptability of students, and effectively improve career planning and enhance the competitiveness of students in employment.

\section{BASIC IDEAS AND METHODS OF CURRICULUM REFORM}

\section{A. Basic Ideas of Curriculum Reform}

1) In-depth understanding of the teaching status of the Career Planning and Employment Guidance course: Through online electronic questionnaires, in-depth interviews with teachers and students, and practice in the classroom, objective 
data are collected as thoroughly as possible. This paper analyzes the current teaching status and teaching effect of the Career Planning and Employment Guidance course, the realistic attitude of teachers and students to the teaching and learning of the Career Planning and Employment Guidance, and faces the problems in the current teaching process. Dialectical analysis of the cause of the problem;

2) Analysis of the characteristics of PBL teaching method: The PBL method has the following four characteristics: (1) With the problem of poor structure as the curriculum organization center and learning situation, the problem is not only the starting point of learning but also the basis for selecting knowledge; (2) Learners play the role of problem holders and solvers, determine the scope of learning according to the situation of the problem and the available resources, understand the problem solving methods and views in various fields through self-directed learning and group learning, and reflect on the connection and solution strategies of old and new knowledge; (3) Adopt a diversified evaluation method. The purpose of PBL evaluation is to show ability of students to provide feedback to students and teachers. The evaluation runs through and integrates into the PBL teaching process, which is an essential component to guide the entire learning process. The evaluation methods are mainly divided into three categories: content, process and results; (4)The teacher plays the role of a mentor. Different from the role of the knowledge transfer in traditional teaching, the teacher needs to shoulder multiple responsibilities in the PBL teaching process, such as the course designer, the student's learning collaborators, supporters and guides, and the evaluators of the learning results;

3) Practical teaching reform in Career Planning and Employment Guidance course by PBL teaching method: This part is the key content of this research. The application of PBL teaching method is divided into the following steps: Teachers ask questions -- group members discuss and analyze problems -- form learning goals -- new problems arise -groups share results -- and summarize and evaluate the process. Accordingly, the class students are divided into several groups based on dormitories and headed by dormitory leaders. The specific implementation process is as follows: (1) The teacher prepares before class. Teachers carefully design and ask questions according to the requirements of the teaching materials and syllabus. For example:"How do you conduct career planning, what are the influencing factors?", "What do you think is the reason for the failure of graduate interviews in this case? How to improve?", and so on, sent to students one week in advance; (2) Students prepare before class. Students should refer to the library or Internetrelated employment information and reference materials according to the layout problems, and read, think, discuss, each student needs to ask new questions or doubts. The team leader organizes the members of the group to discuss in the after-school practice. It is necessary to have a more detailed record of the discussion process, the speech process of each classmate and the results of the discussion, and recommend one or two students as class spokespersons; (3) The class focused on the discussion in the classroom teaching. Each group introduces the conclusions drawn, and the groups exchange opinions and supplement each other. Finally, the instructors summarize and correct the mistakes, and introduce relevant employment knowledge and methods to systematically summarize the key information. (4) Reflection and communication after class. After class, discuss the experience and shortcomings of the group in the process of solving problems, and summarize the gains and experiences after classroom teaching. Teachers can take targeted guidance on the situation of some students.

4) Comparison of the teaching effects between traditional teaching method and PBL teaching method in the course of Career Planning and Employment Guidance: The research team selected two teachers who were in the Career Planning and Employment Guidance course to conduct a comparative study. One of the teachers used the teacher-led regular teaching method, and the other teacher used the PBL teaching method for teaching. The other members of the group tracking the whole course, record the feedback of the students in the course of traditional teaching method and PBL teaching method in the course of Career Planning and Employment Guidance and design the learning effect questionnaire.

According to the characteristics of PBL teaching, combined with the situation of Career Planning and Employment Guidance, design the learning effect questionnaire. The questionnaire is mainly involved to "related professional knowledge defects", "career planning", "cooperation ability", "employment pressure" and other aspects, to intuitively compare the teaching effect of traditional teaching method and PBL teaching method in Career Planning and Employment Guidance.

\section{B. Method of Curriculum Reform}

1) Document analysis: Collect and read relevant documents at home and abroad, summarize the relevant concepts and theories, and put forward the research concepts and problems of this topic;

2) Comparative research method: Walk into the classroom and observe in practice. Learn more about the advantages and disadvantages of the traditional model and the PBL teaching model in the Career Planning and Employment Guidance, and organize the practical materials;

3) Questionnaire survey method: Questionnaires on the teaching effects and recommendations of the Career Planning and Employment Guidance were distributed through an online platform, and to conduct statistical analysis of the questionnaire;

4) In-depth interview method: In conjunction with the content of the questionnaire, select representative teachers and students to conduct round-table interviews. 


\section{THE PRACTICE OF CURRICULUM REFORM}

\section{A. Realizing the Psychological Expectations of Students Through Active Analysis of Academic Conditions}

As everyone knows, teachers who are engaged in the teaching of Career Planning and Employment Guidance of College Students are unlikely to give each student who comes to class a ready-made job. Therefore, this course cannot be taken seriously by students for no reason. If the class teacher fills the classroom and reads the courseware, it will inevitably make the students bored; If the teacher does not pay attention to the students during class, the students are naturally easy to sleep, chat, and play mobile phones; if the case teaching of the teacher makes the students feel unrealistic, there will be no touch on the students' minds. How to combine the psychology of college students into the inner world of college students? This is the key to the success of this research reform study.

\section{B. Using PBL Method in the Form of Transposition Thinking}

1) Taking a good first class: Effectively solve most students' ideological understanding of the importance of the Career Planning and Employment Guidance for College Students. The team has a question in the first lesson of each class: "Which course do you think is the most important in college?" Faced with this question, most of the students answered some core professional courses. The research team gave its own opinion: "There are no courses in the college that are the most important. Any course in the college is the most important!" In the face of seemingly contradictory views, almost all students stared at the teacher with incomprehensible eyes. The research team gave a further interpretation: "University learning is different from secondary school. In the middle school, all the students take the university as the ultimate goal, but the university is different. After graduation, some students choose to take postgraduate degree, some students choose to start a business, and some students choose employment. Different choices bring different learning priorities to college students. Therefore, there is no universal Important courses, every course that you don't think is important, someone realizes its importance. In the university, the real core point is to effectively understand yourself and plan yourself, and choose the direction of employment under the guidance of the teacher. However, how to understand yourself? How to plan yourself? How to choose the direction of development after graduation? This is the problem to be solved in the course of Career Planning and Employment Guidance of College Students".

2) Carrying out the whole process of teaching with problems: Grinding a chopper will not delay the work of cutting firewood, the solution to any problem must be based on the premise of unified thinking, and so must classes. Multiangle analysis of the problem, so that students can find the resonance point in the soul is exactly what everyone thinks is a boring Career Planning and Employment Guidance of College Students.

3) Carrying out case teaching with the example of the side: In the teaching process of applying PBL teaching method, the research group compiled the excellent typical case collections of the school (alumni) for many years. All the cases involved in the setting questions used the outstanding students and outstanding graduates of the school as model case analysis. For example, students who are admitted to graduate schools or graduated students, students who are admitted to teachers with honors, and students who have succeeded in starting a business or graduated students. Before the case teaching, the teachers of the Career Planning and Employment Guidance for College Students first conducted a comprehensive exchange with them to fully understand and collect the life attitudes, learning habits, and career planning of these students during their school days. The positive energy element, during class, communicates with the students in the form of classroom cases, so that the students can contrast and analyze their own problems and deficiencies, find ways and means to motivate and perfect themselves, especially through this kind of example teaching to solve the students' thinking of "passive learning into active learning". For some outstanding students who have not yet graduated, they can invite them to participate in the classroom and discussion, make their own statements, and encourage other students to improve their deficiencies and surpass themselves. Such case teaching can further stimulate students' inner morale and enhance their confidence and urgent desire for success. Under the same environment, others can succeed under the same resource allocation. I can achieve the same success through hard work. Otherwise, if the case teaching is analyzed by great men and celebrities every day, the students will think that they are too far away from themselves, or that the achievements of great men and celebrities are too great, we can't match them at all. Such case teaching is of little significance.

\section{CONCLUSION}

After three years of research on the topic, the theoretical results of the topics such as teaching reform courseware, the paper Analysis of the Practice of PBL Teaching Method in Career Planning and Employment Guidance for College Students, the Case Set of Examples Around the Side and research reports have been formed.

In the course of research on this topic, the school's outstanding alumni' s struggle history in recent years and the typical cases of outstanding students have been compiled into the Case Set of Examples Around the Side to effectively apply to the teaching process of Career Planning and Employment Guidance for College Students. In order to inspire college students to establish firm confidence and life ideals, Remain true to their original aspiration, and strive to achieve their own life goals.

The research results of this topic mainly serve college students. Its social effect is to feed the society by improving the career consciousness and employability of college students, provide more outstanding talents for the society, and achieve the fundamental purpose of providing quality services to the society.

\section{REFERENCES}

[1] He Lifang.Practice and Experience of PBL Teaching Method in Document Retrieval Course[J].Library Work and Study,2007(04); 
[2] Mai Xiaoyu. The Application of PBL Teaching Method in the Teaching of "Professional Development and Employment Guidance Class" [J]. Education and Teaching Forum, 2014 (18);

[3] Zhang Faqing. Research on the Application of PBL Teaching Method in College Student Employment Guidance Courses[J]. Journal of Jincheng Vocational and Technical College, 2012 (3);

[4] Jia Haiyan, Nie Yuemei. The Application of Problem-based Teaching Method in College Students' Employment Guidance Class [J]. Huaxia Teacher, 2012. (3);

[5] Wu Changmin. The Application of Case Teaching Method in College Students' Employment Guidance Course [J]. Ideological Education Research, 2009(12);

[6] Jiang Hui, Wu Yujing, Yao Nian. Talking About the Application of Case Teaching Method in the Employment Guidance Course for College Students [J]. Shanxi Youth, 2016 (3). 